\title{
The exposure of premature newborns with respiratory failure to pain and touch on the first day of hospitalization in the Neonatal Intensive Care Unit - pilot study
}

\author{
GRAŻYNA CEPUCH ${ }^{1, A, E, F}, A G N I E S Z K A ~ K R U S Z E C K A-K R O ́ W K A^{1, B, D}$, \\ ILONA BIEDRA ${ }^{2, B, D}$, MARIA KÓZKA ${ }^{1, A, F}$ \\ ${ }^{1}$ Nursing and Midwifery Institute, Faculty of Health Sciences, Jagiellonian University Collegium Medicum, Cracow, \\ Poland \\ ${ }^{2}$ Department of Pathology and Intensive Care of the Newborn, The University Children's Hospital, Cracow, Poland
}

A - Study Design, B - Data Collection, C - Statistical Analysis, D - Data Interpretation, E - Manuscript Preparation, F - Literature Search, G - Funds Collection

Summary Background. Newborns born prematurely and hospitalized in the Neonatal Intensive Care Unit (NICU) are exposed to stressors, such as touch and pain.

Objectives. The evaluation of exposure of premature babies with respiratory failure to pain and touch generated on the first day of hospitalization at the NICU.

Material and methods. The study group consisted of 11 premature newborns born between 29 0/7 and 35 6/7 weeks of gestation, being on the $1^{\text {st }}$ or $2^{\text {nd }}$ day of life. The observation was carried out on the first day of hospitalization. The research method was based on the standardized observation of newborns for exposure to touch and pain. The NIPS and CRIES scales were used for pain assessment. Results. The study group was exposed to a total of 458 nursing and therapeutic procedures (Me $\left.41 ; Q_{1}-Q_{3}: 39-44\right)$. The nursing team performed 376 touch-related actions on these patients (Me 35; $Q_{1}-Q_{3}: 31-36$ ) and 82 pain-inducing actions (Me 6; $Q_{1}-Q_{3}: 4-11$ ). The average level of pain intensity during individual nursing and therapeutic procedures was Me $3 ; Q_{1}-Q_{3}: 2-4.5$, according to the NIPS scale, and Me $3 ; \mathrm{Q}_{1}-\mathrm{Q}_{3}: 2.5-4.4$, according to the CRIES scale. The most painful procedures were peripheral blood cannulation and venous blood sampling for laboratory testing.

Conclusions. The diagnostic, therapeutic and nursing activities performed by the NICU nursing team are related to excessive touch and induction of pain. Medical teams should regularly assess pain, treat it effectively and strive to reduce stressful touch-related actions. Key words: pain, touch, infant, premature.

Cepuch G, Kruszecka-Krówka A, Biedra I, Kózka M. The exposure of premature newborns with respiratory failure to pain and touch on the first day of hospitalization in the Neonatal Intensive Care Unit - pilot study. Fam Med Prim Care Rev 2018; 20(4): 327-331, doi: https://doi.org/10.5114/fmpcr.2018.79342.

\section{Background}

According to data from the Central Statistical Office, in 2016 in Poland, 28,774 children were born before the $37^{\text {th }}$ week of pregnancy, including 22,314 newborns with a birth weight below 2,500 grams. The percentage of premature births in Poland in recent years has remained at the level of about $6-7 \%$ [1]. Every year in the world, 15 million premature babies are born. About one million of these children die by the end of the first year of life due to prematurity complications. Respiratory distress syndrome (RDS) is the most common respiratory complication of prematurity and the primary cause of respiratory failure in premature infants $[2,3]$.

The development of neonatology that has been observed in recent years has brought about a marked improvement in the survival of premature infants. However, the progress entails more and more diagnostic and therapeutic activities which have a traumatic effect on immature neonates and carry adverse health effects [4]. Pain and touch associated with diagnostic, therapeutic and nursing actions are considered one of the most stressful factors influencing an immature organism. Stress-inducing actions in infants include, among others: suction of secretion from the nasopharynx, capillary and venous blood sampling for laboratory tests, removal of adhesive plasters, in- troduction and removal of a peripheral cannula, an intragastric tube and a catheter from the urinary bladder, intubation, chest physiotherapy, physical examination, bathing, measurements of vital signs and anthropometric parameters, dressing and undressing of a newborn and even changing diapers [5]. Infants born prematurely and hospitalized in the NICU are at risk for pain during almost all of the above-mentioned activities, at the same time they show greater sensitivity to pain than older children and adults. Moreover, the diagnosis and treatment of pain in this group of patients is demanding and intricate.

Touch plays a significant role in the highly specialized medical care of premature newborns. Positive forms of touch are used in the care of newborns hospitalized in intensive care units. These include: continuous, gentle touch, stroking and massage with kinesthetic stimulation and kangaroo care [6]. Touch plays a soothing and stimulating role in the development of premature babies [7]; however, being limited only to diagnostic and therapeutic activities can induce anxiety, which intensifies pain and destabilizes the patient's condition. The reduction of traumatic touch in premature newborns and the systematic assessment of pain intensity are a basis for the implementation of pharmacological and non-pharmacological methods of pain elimination [8]. Comprehensive actions undertaken by medical neonatal teams protect newborns against the negative effects 
of pain and touch in the physical, mental, behavioral and social sphere [9]. They also allow one to reduce the costs of widely-understood medical care in this group of patients.

\section{Objectives}

The evaluation of exposure of premature newborns with respiratory failure to pain and touch generated by the medical actions performed by the nursing team during the first day of hospitalization at the NICU.

\section{Material and methods}

\section{Setting}

The study was conducted in the Neonatal Intensive Care Unit at the Children's Department of the Children's University Hospital in Krakow (Poland). The study group consisted of 11 premature newborns born between $290 / 7$ and 35 6/7 weeks of gestation ( 29 weeks of gestation -6 patients; 30 weeks of gestation -2 patients; 31 weeks of gestation -1 patient; 33 weeks of gestation - 1 patient; 35 weeks of gestation -1 patient), being on the $1^{\text {st }}$ or $2^{\text {nd }}$ day of life. The observation was carried out on the first day of hospitalization. All the neonates were diagnosed with prematurity and respiratory failure in the course of respiratory distress syndrome. The birth weight of the study group ranged from 840 $\mathrm{g}$ to $2,700 \mathrm{~g}$. In the study group, four newborns were subjected to respiration therapy with oxygen at a concentration of $25-60 \%$, and six children were ventilated through the non-invasive nasal CPAP technique (Continuous Positive Airway Pressure) - nCPAP using an Infant Flow device with an oxygen concentration of 21$-50 \%$; one infant received oxygen at a concentration of $30-40 \%$ by nasal cannula using an oxygen supply control device. Nine newborns were placed in a stationary closed-type incubator, and two neonates in an open-type incubator.

The research was approved by the Bioethics Commission of the Jagiellonian University Medical College (No. 122.6120.278.2016 of $27^{\text {th }}$ October 2016). It obtained the consent of the Director of the Children's University Hospital, the head of the Children's Department and the parents of the newborns taking part in the study. All personal and confidential information about the patients is protected.

\section{Participants and variables}

The study excluded premature infants born from twin pregnancies, those with coexisting diseases, congenital or genetic defects, from pregnancies lasting 27 weeks or less, receiving analgesics, sedative or other psychotropic agents.

The research method was based on the standardized observation of newborns for exposure to traumatic factors and the estimation method. Assessment of pain intensity during invasive procedures and analysis of medical records were also conducted. The study used an original questionnaire and the following scales: NIPS (Neonatal Infant Pain Scale) and CRIES (Cry, Requires increased oxygen administration, Increased vital signs, Expression, Sleeplessness). The original questionnaire contained the socio-demographic and clinical data of premature newborns. The questionnaire also included data to assess neonatal exposure to touch based on the frequency of diagnostic, therapeutic and nursing procedures, such as the measurement of vital signs, body length, circumferences and weight, dressing/ /undressing of a newborn, changing diapers, bathing, feeding, intravenous, oral and rectal drug administration, change of dressings and non-invasive collection of the material for diagnostic tests (e.g. urine or stool).

The assessment of pain intensity during painful invasive procedures was conducted using the following instruments:
- NIPS - which evaluates behavioral parameters, such as facial expression, crying, hand placement, lower limb position and the state of arousal. A total of 0 to 7 points can be given in the scale, where 0 points means no pain and 7 points the pain of the highest degree of intensity;

- $\quad$ CRIES scale - which evaluates 5 behavioral and physiological parameters, such as crying, the need for additional oxygen supply, vital signs (heart rate, blood pressure), facial expression and sleep pattern. A total of 0 to 10 points can be given in the scale, where 0 points means no pain and 10 points the pain of the highest degree of intensity.

The exposure of newborns to pain evaluated the following invasive procedures: capillary and venous blood sampling for laboratory testing, peripheral vein cannulation, suction of the contents from an intubation tube (closed system $24 \mathrm{~h}$ ), suction of secretion from the nasopharynx, introduction of an intragastric tube and urinary bladder catheterization. Before the painful procedures, $10 \%$ glucose used per tongue (a few drops) was used.

On the first day of hospitalization, the newborns under study were also exposed to other diagnostic and therapeutic touch-related and pain-inducing procedures, such as ultrasound examinations, auscultation and abdominal palpation. These procedures were not included in the assessment questionnaire, because the study focused on the evaluation of activities performed exclusively by the nursing team.

\section{Statistical methods}

The analysis of data was performed using StatSoft STATISTICA, ver. 13.0 PL, statistics software package and Microsoft Excel. Due to the low number of subjects, it was decided to apply medians $(\mathrm{Me})$ and interquartile ranges $\left(\mathrm{Q}_{1}-\mathrm{Q}_{3}\right)$.

\section{Results}

\section{Diagnostic, therapeutic and care procedures}

On the first day of hospitalization in the Neonatal Intensive Care Unit, the study group of 11 newborns was exposed to a total of 458 diagnostic, therapeutic and nursing activities performed by the nursing team (Me 41; $\mathrm{Q}_{1}-\mathrm{Q}_{3}$ : 39-44).

\section{Touch}

The nursing team performed 376 touch-related actions on these infants (Me 35; $Q_{1}-Q_{3}: 31-36$ ). In the case of the group including 11 newborns under study, on the first day of hospitalization, measurements of vital signs were taken 4 times ( $M e$ 4; $\left.Q_{1}-Q_{3}: 2-4\right)$, body length and circumferences were measured 3 times ( $M e 3 ; Q_{1}-Q_{3}: 2-3$ ), and body weight was measured 2 times (Me 2; $Q_{1}-Q_{3}: 1-2$ ).

Touch-related activities performed most frequently on the first day of hospitalization included the following: changing diapers -7 times daily (Me $7 ; Q_{1}-Q_{3}: 6-8$ ), collecting samples for laboratory tests -5 times per infant (Me $\left.5 ; Q_{1}-Q_{3}: 4-6\right)$, changing of dressings -5 times daily per patient (Me $5 ; Q_{1}-Q_{3}: 4-6$ ), and intravenous drug administration -4 times per patient (Me 4; $\left.Q_{1}-Q_{3}: 3-6\right)$. The exposure of neonates to diagnostic, therapeutic and nursing touch-related activities is shown in Table 1.

\begin{tabular}{|c|c|c|c|}
\hline $\begin{array}{l}\text { Care and therapeutic activi- } \\
\text { ties related to touch }\end{array}$ & $\begin{array}{l}\text { Number of } \\
\text { newborns }\end{array}$ & $\mathrm{Me}$ & $Q_{1}-Q_{3}$ \\
\hline Administration of drugs - i.v. & 11 & 4 & $3-6$ \\
\hline Administration of drugs $-p . o$. & 1 & 1 & $1-1$ \\
\hline
\end{tabular}




\begin{tabular}{|c|c|c|c|}
\hline $\begin{array}{l}\text { Care and therapeutic activi- } \\
\text { ties related to touch }\end{array}$ & \begin{tabular}{|l|l}
$\begin{array}{l}\text { Number of } \\
\text { newborns }\end{array}$ \\
\end{tabular} & Me & $Q_{1}-Q_{3}$ \\
\hline Administration of drugs $-p . r$. & 1 & 1 & $1-1$ \\
\hline Bath & 10 & 1 & $1-1$ \\
\hline Changing the diapers & 11 & 7 & $6-8$ \\
\hline Changing the dressings & 11 & 5 & $4-6$ \\
\hline Feeding & 6 & 6 & $3-8$ \\
\hline $\begin{array}{l}\text { Measurements of body length } \\
\text { and circumferences }\end{array}$ & 11 & 3 & $2-3$ \\
\hline $\begin{array}{l}\text { Measurements of body pa- } \\
\text { rameters }\end{array}$ & 11 & 4 & $2-4$ \\
\hline $\begin{array}{l}\text { Taking samples for laboratory } \\
\text { tests (blood, urine, pharyngeal } \\
\text { swabs) }\end{array}$ & 11 & 5 & $4-6$ \\
\hline Weighing & 11 & 2 & $1-2$ \\
\hline
\end{tabular}

i.v. - intra venosum (intravenously); p.o. - per os (orally); p.r. - per rectum (rectally); $\mathrm{Me}-$ median, $\mathrm{Q}_{1}-\mathrm{Q}_{3}-$ interquartile ranges.

\section{Pain}

There were 82 pain-inducing procedures performed in the entire study group on the first day of hospitalization (Me 6; $Q_{1}-Q_{3}: 4-11$ ). During the first day, capillary blood samples were taken in 6 newborns (Me $\left.1 ; Q_{1}-Q_{3}: 1-1\right)$. Venous blood sampling was performed in 4 neonates (Me $\left.1 ; Q_{1}-Q_{3}: 1-1\right)$; peripheral vein cannulation was performed in 6 neonates (Me $1 ; Q_{1}-Q_{3}$ : 1-1) - once in each case.

Only certain studied neonates required peripheral vein cannulation, because some of them already had a peripheral vascular access placed, for example, in delivery room. It was possible to limit the pain and anxiety associated with invasive procedures in the admitted newborns with an arterial line in place. In addition, not all neonates had capillary and venous blood collected for laboratory testing.

On the first day of hospitalization, nasopharyngeal secretion was suctioned in the case of 9 newborns -3 times per day (Me 3; $\left.Q_{1}-Q_{3}: 2-3\right)$, whereas the intubation tube contents in 6 newborns -4 times (Me 4; $Q_{1}-Q_{3}: 2-6$ ). An intragastric tube was placed in 10 patients - once per day (Me $\left.1 ; Q_{1}-Q_{3}: 1-2\right)$. The above-mentioned data is presented in Table 2.

\begin{tabular}{|c|c|c|c|}
\hline $\begin{array}{l}\text { Pain-inducing actions performed } \\
\text { by the nursing team }\end{array}$ & $\begin{array}{l}\text { Number of } \\
\text { newborns }\end{array}$ & Me & $\mathrm{Q}_{1}-\mathrm{Q}_{3}$ \\
\hline $\begin{array}{l}\text { Capillary blood sampling for labora- } \\
\text { tory testing }\end{array}$ & 6 & 1 & $1-1$ \\
\hline Introduction of intragastric tube & 10 & 1 & $1-2$ \\
\hline Peripheral vein cannulation & 6 & 1 & $1-1$ \\
\hline $\begin{array}{l}\text { Suction of nasopharyngeal secre- } \\
\text { tion }\end{array}$ & 9 & 3 & $2-3$ \\
\hline Suction of intubation tube contents & 6 & 4 & $2-6$ \\
\hline Urinary bladder catheterization & 0 & 0 & 0 \\
\hline $\begin{array}{l}\text { Venous blood sampling for labora- } \\
\text { tory testing }\end{array}$ & 4 & 1 & $1-1$ \\
\hline
\end{tabular}

Me-median; $Q_{1}-Q_{3}-$ interquartile ranges.

The average level of pain intensity during individual nursing and therapeutic procedures was $\mathrm{Me}-3 ; \mathrm{Q}_{1}-\mathrm{Q}_{3:} 2-4.5$ according to the 7-point NIPS scale, and $\mathrm{Me}-3 ; \mathrm{Q}_{1}-\mathrm{Q}_{3}: 2.5-4.4$ according to the 10-point CRIES scale. The greatest pain was associated with peripheral vein cannulation and venous blood sampling for laboratory testing - the details are provided in Table 3.

\begin{tabular}{|l|l|l|}
\hline \multicolumn{3}{|l|}{$\begin{array}{l}\text { Table 3. Pain intensity in preterm newborns during nursing } \\
\text { practice evaluated according to NIPS and CRIES scales }\end{array}$} \\
\hline $\begin{array}{l}\text { Pain inducing activities in } \\
\text { newborns }\end{array}$ & $\begin{array}{l}\text { NIPS } \\
{\left[\mathrm{Me} ; \mathbf{Q}_{1}-\mathbf{Q}_{3}\right]}\end{array}$ & $\begin{array}{l}\text { CRIES } \\
{\left[\mathrm{Me} ; \mathbf{Q}_{1}-\mathbf{Q}_{3}\right]}\end{array}$ \\
\hline $\begin{array}{l}\text { Capillary blood sampling } \\
\text { for laboratory testing }\end{array}$ & $3.5 ; 2-5$ & $3 ; 3-5$ \\
\hline $\begin{array}{l}\text { Introduction of intragastric } \\
\text { tube }\end{array}$ & $2 ; 1.5-3.5$ & $3 ; 2.5-3$ \\
\hline Peripheral vein cannulation & $4.75 ; 4-6$ & $4.5 ; 4-6$ \\
\hline $\begin{array}{l}\text { Suction of nasopharyngeal } \\
\text { secretion }\end{array}$ & $3.3 ; 2.5-4$ & $4 ; 2.5-4.3$ \\
\hline $\begin{array}{l}\text { Suction of intubation tube } \\
\text { contents }\end{array}$ & $2.45 ; 2-3$ & $2.75 ; 2-3.6$ \\
\hline $\begin{array}{l}\text { Venous blood sampling for } \\
\text { laboratory testing }\end{array}$ & $4.75 ; 3.5-6$ & $5 ; 3.5-6$ \\
\hline
\end{tabular}

Me - median; $Q_{1}-Q_{3}-$ interquartile ranges.

\section{Discussion}

\section{Key results}

Hospitalization in the Neonatal Intensive Care Unit (NICU) is necessary for the survival of premature newborns, but this involves exposing them to traumatic factors, such as pain, artificial light, noise, touch and separation from parents $[10,11]$. Studies confirm that exposure to these agents during the neonatal period can cause numerous neurobehavioral disorders, which can have a negative impact on later developmental stages [12].

The results of this original study show that during the first day of hospitalization in the NICU, one neonate was subjected to about 42 touch-related and pain-inducing actions performed by the nursing team. This is slightly less than on the first day of hospitalization of newborns in the cardiology ward of the same hospital [5]. It should be noted, however, that the group of newborns taking part in our study were children born prematurely with a diagnosis of RDS, while the newborns from the cardiology ward were full-term babies, which could affect the number of touch-related and pain-inducing activities.

The level of pain experienced by the study group and assessed using the recommended scales was similar. Peripheral blood cannulation and venous blood sampling for laboratory testing were the most painful. Slightly lower results were obtained by Rohan [13, 14], who studied a group of ventilated premature children. The author of the cited study reported a significant number of painful procedures that newborns were subjected to, especially within the first three days after birth. On the other hand, the studies conducted in the cardiologic ward show that the suction of secretion from the nasopharynx was the most painful procedure -7 points in the CRIES [5]. The pain associated with diagnostic and therapeutic procedures has a negative impact on brain function. Mainous and Looney [15] points out the relationship between a heel lance for diagnostic tests and cerebral blood flow changes leading to intraventricular hemorrhage. A relationship between pain and the brain function was also reported by other authors [16], who recommend actions aimed at preserving the well-being of the brain in immature newborns.

An analysis of scientific reports and our study show that on the first day of hospitalization in neonatal departments, infants are subjected to pain-inducing activities. Premature babies are a particularly vulnerable group that requires respiratory support or replacement. Prolonged intubation is associated with the possibility of complications, including the most common, i.e. laryngeal edema, laryngotracheobronchitis and bedsores [17]. Intubation and artificial ventilation are painful and stressful experiences for the newborn [18]. Respiratory patency is a prerequisite for effective ventilation; therefore, mechani- 
cally non-invasively ventilated patients require the evacuation of respiratory secretion. On the other hand, the measurement of capillary blood gases is an essential part of monitoring the effectiveness of therapy. The establishment of an arterial line for painless blood sampling should be considered to minimize traumatic experiences [19]. Establishing a central vascular line limits the exposure of newborns to painful procedures during long-term intravenous or parenteral treatment. Medical care for premature babies should take into account the fact that they may not fully express a feeling of pain, as their nervous system is immature [20], and sleep can be a symptom of exhaustion and not the lack of pain. The restrictive adherence to recommendations aimed at limiting neonatal exposure to pain-inducing stimuli, pain assessment and its effective elimination are crucial for the patient's well-being $[12,19,21]$. Despite extensive research conducted in this group of patients on the impact of pain on the functioning of the brain $[20,22]$ and previous reports signaling the problem of pain, pain evaluation and treatment still appear to be unsystematic and require unification.

Touch is one of the ways to relieve pain. It has a positive effect on the development of immature newborns, as it soothes, calms and relieves pain $[7,10]$. However, when touch is too frequent and intense, it can become a source of stress for the newborn. The principle of "minimal handling", which assumes the reduction and accumulation of diagnostic, therapeutic and nursing procedures, is recommended for NICU medical teams. Despite the fact that the nursing team taking care of the neonates followed the "minimal handling" principle, the number of stressful touch-related actions performed on the first day of hospitalization was about 34 per one newborn. The most common touch-related activity was the change of diapers. Given the immaturity of the nervous system and the need for continuous sleep, traumatic touch-related and pain-inducing actions can be considered key predictors of immature newborns condition destabilization.

More thorough understanding of the problem of neonatal exposure to traumatic factors in the NICU requires continued research conducted in this group of patients and the implementation of measures to improve the effectiveness of pain assessment and treatment [23]. Effective pain management, which is a desirable standard of care for premature and term newborns, may potentially improve clinical and neurodevelopmental outcomes. Despite the limitations of currently available tools, neonatal pain should be assessed routinely using context-specific, validated and objective pain evaluation methods. The management of neonatal pain should be implemented by reducing the number of invasive procedures and using pharmacological, behavioral and environmental measures [24]. It would also be desirable to develop educational programs for NICU nursing teams [25] in order to more effectively integrate them into the process of reliable pain assessment and treatment using non-pharmacological and pharmacological methods in the range of their professional responsibility. A collaborative partnership of physiotherapists and nurses should also be promoted to motivate these interventions. Combating traumatic experiences, which favors faster recovery and shortens the stay of premature neonates in the hospital ward, is important to their further development. A greater number of days spent in the NICU is associated with worse neurodevelopmental outcomes [26]. The shortening of hospitalization is also important for economic reasons, because it reduces the financial costs of maintaining the well-being of newborns.

\section{Limitations of the study}

The limitations of the study were the small group of the subjects and no control group (e.g. a group of newborns without parents). We are aware of the limitations of our study, and the above limitations may have influenced the results obtained. Our studies only signal the problem and provide an introduction to further work.

\section{Interpretation and generalizability}

The analysis of our results and scientific reports indicate the need for a comprehensive, personalized approach to the difficult situation of a premature newborns in the face of an illness and factors destabilizing the condition. Popularization of the study area can improve the health of newborns and reduce the cost of treatment. The research tools are easy to use and can be applied by nursing and physicians. They serve for the examination of premature newborns, enabling one to objectify the results in different age groups.

\section{Conclusions}

On the first day of hospitalization, premature newborns are subjected to a large number of traumatic touch-related and pain-inducing procedures performed by the nursing team. Medical teams taking care of immature newborns should strive to conduct solid and regular pain assessment, perform effective treatment and reduce potential stress-inducing actions and factors. Primary care physicians and nurses should be involved in the process of preparing parents for the care of a premature baby after discharge from the hospital, taking into account the "minimal handling" principle and the use of positive forms of touch supporting the child's development.

Source of funding: This work was funded by university funds.

Conflicts of interest: The authors declare no conflicts of interest.

\section{References}

1. Główny Urząd Statystyczny. Rocznik demograficzny 2016. Warszawa: Zakład Wydawnictw Statystycznych; 2016: 297,378 (in Polish).

2. Reuter S, Moser C, Baack M. Respiratory distress in the newborn. Pediatr Rev 2014; 35(10): 417- 429, doi: 10.1542/pir.35-10-417.

3. Saboute $M$, Kashaki M, Bordbar A, et al. The incidence of respiratory distress syndrome among preterm infants admitted to Neonatal Intensive Care Unit: a retrospective study. Open J Pediatr 2015; 5(4): 285-289, doi: 10.4236/ojped.2015.54043.

4. Rohan AJ. Pain-associated stressor exposure and neuroendocrine values for premature infants in neonatal intensive care. Dev Psychobiol 2016; 58(1): 60-70, doi: 10.1002/dev.21346

5. Cepuch G, Gniadek A, Bytowska N. The assessment of neonates' exposure to traumatic factors in the cardiac ward within the first 24 hours of hospitalization. Med Środow 2016; 19(1): 17-24.

6. Pagni AM, Kellar S, Rood M. Effects of kangaroo care on procedural pain in preterm infants: a systematic review. Honors Research Projects 2017; 441. Available from URL: http://ideaexchange.uakron.edu/honors_research_projects/441.

7. Alvarez MJ, Fernandez D, Gomez-Salgado J, et al. The effects of massage therapy in hospitalized preterm neonates: a systematic review. Int J Nurs Stud 2017; 69: 119-136, doi: 10.1016/j.ijnurstu.2017.02.009.

8. Abdallah B, Badr LK, Hawwari M. The efficacy of massage on short and long term outcomes in preterm infants. Infant Behav Dev 2013; 36(4): 662-669, doi: 10.1016/j.infbeh.2013.06.009.

9. Gyland EA. Infant pain assessment: a quality improvement project in a level III Neonatal Intensive Care Unit in Northeast Florida. Newborn Infant Nurs Rev 2012; 12(1): 44-50, doi: 10.1053/j.nainr.2011.12.007. 
10. Flacking R, Lehtonen L, Thomson G, et al. Closeness and separation in neonatal intensive care. Acta Paediatr 2012; 101(10): 1032-1037, doi: 10.1111/j.1651-2227.2012.02787.x.

11. d'Agata AL, Young EE, Cong X, et al. Infant medical trauma in the Neonatal Intensive Care Unit (IMTN). Adv Neonatal Care 2016; 16(4): 289-297, doi: 10.1097/ANC.0000000000000309.

12. Lee JH, Espinera AR, Chen D, et al. Neonatal inflammatory pain and systemic inflammatory responses as possible environmental factors in the development of autism spectrum disorder of juvenile rats. J Neuroinflammation 2016; 13: 109, doi: 10.1186/s12974-016-0575-x.

13. Rohan AJ. Efficacy of current practices for pain assessment in premature ventilated infants in the NICU. Exposed to a high number of pain-associated procedures. MCN Am J Matern Child Nurs 2015; 40(6):367-372, doi: 10.1097/NMC.0000000000000184.

14. Rohan AJ. The utility of pain scores obtained during 'regular reassessment process' in premature infants in the NICU. J Perinatol 2014; 34(7): 532-537, doi: 10.1038/jp.2014.57.

15. Mainous RO, Looney SA. Pilot study of changes in cerebral blood flow velocity, resistance, and vital signs following a painful stimulus in the premature infant. Adv Neonatal Care 2007; 7(2): 88-104.

16. Grunau RE. Neonatal pain in very preterm infants: long-term effects on brain, neurodevelopment and pain reactivity. Rambam Maimonides Med J 2013; 4(4): e0025, doi: 10.5041/RMMJ.10132.

17. Khatami SF, Parvaresh P, Behjati S. Common complications of endotracheal intubation in newborns. Iran J Neonatolo 2011; 2(2): 12-17.

18. Gjerstad AC, Hellerud BC, Wagner K, et al. Skin conductance as a measure of discomfort in artificial ventilated children. Pediatrics 2008; 122(4): e848-e853.

19. Witt N, Coynor S, Edwards C, et al. A guide to pain assessment and management in the neonate. Curr Emerg Hosp Med Rep 2016; 4: 1-10, doi: 10.1007/s40138-016-0089-y.

20. Fabrizi L, Slater R, Worley A, et al. A shift in sensory processing that enables the developing human brain to discriminate touch from pain. Curr Biol 2011; 21: 1552-1558, doi: 10.1016/j.cub.2011.08.010.

21. Lym Y, Godambe S. Prevention and management of procedural pain in the neonate: an update, American Academy of Pediatrics, 2016. Arch Dis Child Educ Pract Ed 2017; 102(5): 254-256, doi: 10.1136/archdischild-2016-311066.

22. Brummelte S, Grunau RV, Chau V, et al. Procedural pain and brain development in premature infants. Ann Neurol 2012; 71: 385-396, doi: 10.1002/ana.22267.

23. Maxwell LG, Malavolta CP, Fraga MV. Assessment of pain in neonate. Clin Perinatol 2013; 40(3): 457-469, doi:10.1016/j.clp.2013.05.001.

24. Hall RW, Anand KJS. Pain management in newborns. Clin Perinatol 2014; 41(4): 895-924, doi: 10.1016/j.clp.2014.08.010.

25. Pölkki T, Korhonen A, Laukkala H, et al. Nurses' attitudes and perceptions of pain assessment in neonatal intensive care. Scand $\mathrm{J}$ Caring Sci 2010; 24(1): 49-55, doi: 10.1111/j.1471- 6712.2008.00683.x.

26. Jarjour IT. Neurodevelopmental outcome after extreme prematurity: a review of the literature. Pediatr Neurol 2015; 52(2): 143-152, doi: 10.1016/j.pediatrneurol.2014.10.027.

Tables: 3

Figures: 0

References: 26

Received: 03.12.2017

Reviewed: 03.01.2018

Accepted: 29.01.2018

Address for correspondence:

Grażyna Cepuch, PhD

Zakład Pielęgniarstwa Klinicznego

Instytut Pielęgniarstwa i Położnictwa UJ CM

ul. Kopernika 25

31-501 Kraków

Polska

Tel.: +48 600 132-585

E-mail: grazyna.cepuch@uj.edu.pl 